\title{
O DESENVOLVIMENTO POLÍTICO EM HUNTINGTON E FUKUYAMA
}

Natália Nóbrega de Mello

Há pouco mais de quarenta anos, Samuel Huntington lançou Ordem política nas sociedades em mudança, livro em que continuou a polêmica tratada em seu artigo "Desenvolvimento político e decadência política" de 1965. Nestes trabalhos, ele defendeu, na contramão das teorias sobre desenvolvimento político de então, que uma teoria da decadência era a mais apta para se entender as "sociedades em mudança". O autor abandonou a crença de que o desenvolvimento político era o destino inevitável dessas sociedades ao afirmar que a reversão dos avanços já alcançados por elas seria sempre uma possibilidade. Huntington disse ainda que a modernização social, longe de levar ao desenvolvimento político - como defendia a perspectiva clássica ${ }^{1}$-, gerava instabilidade e decadência política. No lugar da modernização, o objetivo que esses países deveriam perseguir era o da ordem política (Huntington, 1965; 1968).

\footnotetext{
${ }^{1}$ Algumas perspectivas clássicas acerca da relação entre modernização e desenvolvimento político, contra as quais Huntington se contrapõe, são as de Lerner (1964), Almond e Coleman (1969), Shils (1960) e Deutsch (1961).
} 
Se compreendermos como uma ruptura do discurso político, conforme define Pocock (2003), aquela mudança de linguagem que altera o eixo do diálogo, então, podemos dizer que, de fato, Huntington rompeu com o discurso político anterior, uma vez que reorientou o diálogo para o eixo da estabilidade, e não mais o da democracia; para a proposição de fortalecimento das instituições e da ordem política, no lugar das propostas de modernização e desenvolvimento econômico. Ao romper com os clássicos do desenvolvimento político de seu tempo, Huntington transformou-se, por sua vez, no cânone dessa nova linha de pesquisas que fez emergir.

Um survey realizado por Kenski, em 1974, indicou a importância do livro de Huntington para o estabelecimento dessa nova linguagem da ciência política. Segundo esse survey, os cientistas apontaram majoritariamente o livro Ordem política nas sociedades em mudança como a obra mais importante $(57,6 \%)$ e também a mais útil $(59,4 \%)$ para a teoria do desenvolvimento político (Kenksi, 1975). Além disso, para os entrevistados, o desenrolar da nova linha de pesquisa seria o "período auge" ou a "década de ouro" dessa teoria. Naquele período, a política comparada teria se tornado um grande lócus de construção e inovação teórica no interior da ciência política (Schmitter, 1991), ao indicar caminhos profícuos até para a compreensão da sociedade norte-americana (Wiarda, 1991). Por esses motivos, essa área temática teria atraído os melhores alunos e, mais do que isso, tinha grande relevância para a política externa dos Estados Unidos (Wiarda, 1998).

A questão da relevância da teoria do desenvolvimento político para a política externa é de extrema importância para este artigo. Em primeiro lugar, porque o ano da publicação de Ordem política nas sociedades em mudança (1968) marca não só uma inflexão na teoria do desenvolvimento político, mas também na própria política externa 
dos Estados Unidos com Ásia, África e América Latina. Em segundo lugar, ambas inflexões apresentam significativas semelhanças entre si: a ascensão da problemática da ordem e da estabilidade, de um lado, e o quase desaparecimento daquela da modernização e da transformação social, por outro. Fukuyama defende, em recente prefácio à reedição dessa obra de Huntington, que não é mera coincidência o livro ter sido publicado em um ano em que a política norte-americana - guiada por estratégias de desenvolvimento como alternativas para os apelos do comunismo -, deu sinais de esgotamento. Neste contexto, Huntington

sugeriu que existia um caminho adiante por meio do autoritarismo modernizante. [...] traçou, então, o fundamento para uma estratégia de desenvolvimento que passou a ser chamada de "transição autoritária", a qual uma ditadura modernizante fornecia ordem política, o primado da lei e condições para o sucesso do desenvolvimento social e econômico (Fukuyama, 2006a, p. xiii).

Apesar das afinidades entre os fatos políticos e teóricos, chama atenção que as inúmeras análises sobre eventos de 1968, seus efeitos naquela conjuntura histórica e a reação política àquele ano decisivo pouco discutiram sobre a inflexão ocorrida naquele contexto na relação entre os Estados Unidos e os países pobres, menos ainda sobre a inflexão na teoria do desenvolvimento político e sobre as possíveis relações entre ambas transformações.

O grau de ruptura com a perspectiva clássica anterior e o impacto gerado nas novas gerações configurariam a obra de Huntington como um objeto de estudo privilegiado para o desenvolvimento da linha de pesquisa mencionada acima. No entanto, a despeito dessa importância, a análise de Huntington tem sido desconsiderada hoje em dia. 
Essa negligência poderia ser explicada pela distância que nos separa da fundação de sua linha de pensamento, bem como da política externa que foi uma reação ao desenvolvimentismo clássico. Em suma, a construção da ordem política como questão prioritária em relação à luta pela democracia ou modernização social pode parecer um assunto defasado depois da "terceira onda de democratização" ou após o "fim da história”. Segundo essa linha de raciocínio, o próprio Huntington ao publicar A terceira onda: a democratização no final do século XX, estaria ciente que a sua obra de 1968 havia sido ultrapassada pelos acontecimentos históricos (Huntington, 1994).

Parece ponto pacífico entre os pesquisadores que a mais forte rejeição, no campo do pensamento, ao sombrio quadro de decadência política traçado por Huntington acerca do presente e do futuro das sociedades em mudança, foi de Francis Fukuyama em seu artigo de 1989, posteriormente transformado em livro, O fim da história. Se Huntington afirmou que 100 as sociedades em mudança estavam em meio a um processo de decadência política e que o desenvolvimento político era incerto, Fukuyama, por sua vez, reafirmou a projeção clássica de que o destino desses países seria a democracia liberal ocidental, sistema que saíra triunfante da disputa com o comunismo e que, a longo prazo, venceria em todos os países.

Será então que a questão de Ordem política nas sociedades em mudança se encontra completamente obsoleta no pensamento e na realidade política atual? A mera proliferação de estudos sobre os Estados fracassados ${ }^{2}$, campo de pesquisas que conta com a participação do próprio Fukuyama, indica que não estamos tão distantes da preocupação com a deca-

\footnotetext{
${ }^{2} \mathrm{O}$ termo vem da noção failed states que, em português, tem sido traduzida pela expressão "Estados falidos". Opto aqui pela tradução "Estados fracassados", pois os termos "falido" ou "falência" remetem, mais comumente, em nosso idioma, à noção de falência econômica, o que compromete, do meu ponto de vista, o sentido original do conceito, que trata sobretudo dos aspectos políticos desse fracasso. Sobre essa tradução, ver também Monteiro (2006).
} 
dência política quanto se poderia irrefletidamente afirmar. Sem pretender, então, assumir a linha de raciocínio acima desenvolvida, ainda assim este artigo considera uma questão de grande relevância entender e discutir quais foram as transformações no pensamento norte-americano sobre desenvolvimento político entre o seu ano de inflexão inicial (1968) e outro ano decisivo (1989), data da queda do muro de Berlim e marco do desmonte da União Soviética. Para fazer isso, este artigo elege como objeto de estudo as obras de Samuel Huntington (1965; 1968) e os textos de Francis Fukuyama (1989; 1992a). Curiosamente, nos dois casos, trata-se de trabalhos que surgiram primeiramente como artigos e depois foram desenvolvidos em livro. A escolha dessas obras não pressupõe que elas são completamente representativas do seu tempo - não no sentido de poderem representar a totalidade dos trabalhos escritos no período, nem no de que existiria qualquer consenso no debate. Aqui se entende tão-somente como justificativa de uma comparação dessa natureza, o caráter determinante das duas obras com relação ao problema do desenvolvimento e ao impacto de ambas no pensamento político, tal como foram expostos acima.

Dois pontos principais são objeto de análise em cada um dos autores: a definição de desenvolvimento político e o modo como entendem a diferença entre os países pobres e ricos. Ao fim, o artigo discute se a obra de Fukuyama representa realmente uma rejeição da ênfase na decadência política formulada por Samuel Huntington e, para isso, lança mão de algumas obras mais recentes de Fukuyama.

\section{Samuel Huntington: o divórcio entre modernização e institucionalização}

A preocupação de Huntington em distinguir desenvolvimento político e modernização é o elemento-chave para entender a definição que emerge de cada um desses conceitos. Segundo ele, o uso do conceito de desenvolvimento políti- 
co pela bibliografia clássica, entre a década de 1950 e início da seguinte, ao invés de precisar o seu significado, apenas o confunde com o de modernização. Ele afirma que, apesar de existir uma multiplicidade de definições para o desenvolvimento político, é possível identificar duas características que aparecem nestas diferentes abordagens. Em primeiro lugar, ele é geralmente identificado, ou está intimamente conectado, com algum aspecto da modernização da sociedade como um todo. Por consequência, em segundo lugar, é necessário o uso de uma série de critérios para medir o desenvolvimento político, já que a modernização é um processo amplo e complexo. No artigo de 1965, Huntington aponta como esses critérios a racionalização, a integração, a democratização e a participação; mas, já no livro de 1968, apenas a racionalização, a diferenciação e a participação são considerados.

A diferenciação entre desenvolvimento político e modernização permitiria a obtenção de um conceito mais 102 preciso e universal, uma vez que não mais se restringiria à análise de países em modernização e, assim, tornaria possível utilizá-lo para a investigação de antigas civilizações e impérios. Com isso, o conceito de desenvolvimento político se libertaria de uma identificação estrita com o Ocidente e, ainda, conseguir-se-ia alcançar clareza a respeito do que é específico atualmente no processo em curso na Ásia, na África e na América Latina. Além disso, se o objetivo é entender o desenvolvimento político dessas regiões do mundo, essa diferenciação é necessária, já que nelas a modernização, em certo sentido, é um fato, enquanto o desenvolvimento político não reflete nem de longe sua realidade, que é marcada por violências, golpes, corrupção etc. $\mathrm{O}$ uso de variáveis da modernização para medir o suposto desenvolvimento político desses países gera uma falsa sensação de que eles estão progredindo e, até mesmo, que isso seria inevitável; na realidade, as sociedades em mudança estão em meio à decadência política. 
Dois fenômenos definem a marcha da modernização: a mobilização social e o desenvolvimento econômico. Huntington assume a definição de Deutsch (1961) para mobilização social, isto é, o fenômeno por meio do qual antigos comprometimentos são destruídos e novos padrões de comportamento e socialização emergem. Segundo Huntington, a mobilização social afeta diretamente a política porque altera as aspirações de indivíduos, grupos ou sociedades. Já o desenvolvimento econômico é relevante porque transforma a capacidade destes mesmos atores. Portanto, a modernização social é um processo que envolve, de um lado, mudanças nas aspirações dos indivíduos e, de outro, nas suas capacidades. A instabilidade seria o resultado da incapacidade de satisfazer os novos desejos criados.

Essa compreensão da causa da instabilidade no processo de modernização não é inédita e, na verdade, já aparecia nos clássicos do desenvolvimento político (Lerner, 1964; Deutsch, 1961; Shils, 1960a; 1960b). A originalidade de Huntington está no abandono de qualquer presunção de uma modernização que, ao fim, possa ser estável e benéfica; ela deixa de ser vista sequer como desejável ${ }^{3}$. A citação abaixo indica como a manutenção de uma estrutura social de indivíduos menos conscientes e reivindicadores é compreendida por este cientista político como uma

\footnotetext{
${ }^{3}$ A questão da instabilidade entre os clássicos não tornava indesejável a modernização: "Tais intervenções não devem ter o objetivo de retardar o desenvolvimento econômico e social. [...] Essas políticas [policies] de desaceleração da mobilização social e do desenvolvimento econômico, essencialmente, apenas reduziram as capacidades do governo, construíram o caminho para fracassos domésticos e derrotas internacionais e foram seguidas, ao longo do curso de três gerações, pelo atraso persistente e pela destruição final do Estado. Uma política [policy] mais promissora seria, ao contrário, uma ação interventora a favor de um crescimento mais rápido e balanceado; uma distribuição de renda de alguma forma mais uniforme, relacionada mais proximamente às recompensas das contribuições produtivas que ao status e à herança; um investimento mais produtivo dos recursos disponíveis; e um crescimento sustentável das capacidades administrativas e políticas do governo e dos estratos cada vez mais amplos da população" (Deutsch, 1961, p. 505).
} 
alternativa possível frente a uma modernização essencialmente desestabilizadora:

Existe assim um conservadorismo dos desamparados tão profundo quanto o dos privilegiados; os primeiros constituem um fator tão importante para a perpetuação da ordem social quanto os últimos. A pobreza em si mesma é uma barreira à instabilidade. Os que estão preocupados com o objetivo imediato da próxima refeição não estão propensos a se preocuparem com a grande transformação da sociedade (Huntington, 1975, p. 66) ${ }^{4}$.

A modernização é entendida como um processo essencialmente desestabilizador e até mesmo indesejável, e o desenvolvimento político como o processo de institucionalização de organizações políticas e procedimentos, isto é, o "processo por meio do qual organizações e procedimentos 104 adquirem valor e estabilidade" (Huntington, 1965, p. 394; 1975 , p. 24) ${ }^{5}$. Dessa forma, é justamente a existência de procedimentos reconhecíveis e estáveis capazes de regular a participação política e os conflitos que garantiria a estabilidade das sociedades. A citação abaixo indica esse ponto:

Tanto a sociedade de massa quanto a sociedade participante possuem elevados níveis de participação política.

Diferem, porém, na institucionalização das organizações e dos procedimentos políticos. Na sociedade de massa, a participação política é não estruturada, inconstante, anômica e variada. Cada força social procura atingir seus

\footnotetext{
${ }^{4}$ Sobre as favelas e a população rural, ver Huntington (1975, pp. 288, 440). Sob uma perspectiva mais ampla, na mesma obra, o autor ainda explica por que são os países em modernização (e não os pobres e tradicionais) os mais instáveis (Huntington, 1975, pp. 52-60).

${ }^{5} \mathrm{O}$ institucionalismo presente em Huntington é, portanto, bastante diferente das questões existentes nas duas vertentes célebres da ciência política (a clássica e o neoinstitucionalismo).
} 
objetivos através dos recursos e das táticas em que é mais forte. A apatia e a revolta se sucedem uma a outra, filhas gêmeas da ausência de símbolos e instituições políticas com autoridade. A forma característica de participação política é o movimento de massa, combinando ações violentas e não violentas, legais e ilegais, coercitivas e persuasivas. A sociedade de massa carece de estruturas organizadas que possam relacionar os desejos e atividades políticas das massas com os objetivos e decisões de seus líderes (Huntington, 1975, p. 101).

Em uma frase: se a modernização seria responsável pelos efeitos desestabilizadores, o desenvolvimento político é aquele que gera a estabilidade. Essa diferenciação aparece claramente na citação a seguir:

A instabilidade da cidade - a instabilidade dos golpes, das insurreições, das demonstrações - é, até certo ponto, uma característica inevitável da modernização. A extensão que essa instabilidade se manifesta depende da eficiência e legitimidade das instituições políticas da sociedade (Huntington, 1975, p. 90).

Resta ainda analisar como essa nova perspectiva sobre o desenvolvimento político transforma o modo de compreender as diferenças entre os países politicamente desenvolvidos e aqueles que ainda não chegaram lá.

\section{Âncoras versus velas}

Ainda na introdução de Ordem politica nas sociedades em mudança, Huntington apresenta uma classificação esquemática das diferentes sociedades a partir de dois critérios: participação e institucionalização. As sociedades modernas são aquelas com alta participação, subdivididas entre desenvolvidas (em que é alta a participação e a institucionaliza- 
ção) e subdesenvolvidas (em que a institucionalização é baixa). Uma segunda clivagem refere-se apenas ao grau de institucionalização política (deixando, de lado, portanto, a participação). As altamente institucionalizadas são sociedades cívicas, enquanto as de baixo grau são pretorianas. Ao longo do desenvolvimento do argumento do autor, diversas características aparecem para substancializar o esquema classificatório inicial.

A primeira característica através da qual Huntington entende a identidade das sociedades em mudança aparece simbolicamente na imagem que ele toma emprestado de Thomas Macaulay: "sociedades que são toda vela e nenhuma âncora”. A instabilidade é, portanto, a marca dessas sociedades. Mas o que Huntington entende por âncoras? Uma análise da identidade dos países desenvolvidos permite responder a essa pergunta. As características principais desses países são: a existência de uma comunidade políti106 ca definida, legitimidade, uma visão comum do interesse público, instituições fortes, adaptáveis e coesas e a lealdade dos cidadãos (Huntington, 1975, p. 13). Essas características podem ser vistas como as âncoras da sociedade, ou seja, aquilo que até hoje mantém a estabilidade quando o sistema é desafiado por novas questões. São elas que mantêm a sociedade estável frente a novos desafios, como exemplifica em sua análise da dificuldade do sistema político norteamericano em assimilar a minoria negra, tal como é apresentado abaixo:

Os problemas do sistema político norte-americano na década de 1960 de assimilar a minoria negra não diferiam significativamente dos enfrentados por muitos sistemas políticos em países em modernização. Entretanto, no passado, o sistema político americano e os partidos americanos demonstraram capacidade institucional precisamente para essa assimilação. A absorção bem- 
sucedida dos karens, dos tamiles, dos curdos ou dos negros nos sistemas políticos da Birmânia, do Ceilão, do Iraque ou do Sudão era muito mais problemática simplesmente porque as elites políticas desses países não tinham procedimentos tão altamente desenvolvidos e institucionalizados para manejar esses problemas (Huntington, 1975, p. 405).

Já os países em mudança não possuem nenhuma dessas âncoras: a comunidade política é fragmentada, as instituições são fracas e sem flexibilidade, os regimes políticos estão em constante transformação.

Huntington reflete sobre a história dos países desenvolvidos que possibilitou a geração dessas âncoras em contraste com o processo de modernização dos países da Ásia, África e América Latina. A resposta encontrada é basicamente aquela que outros teóricos do desenvolvimento político já haviam dado: a Europa e os Estados Unidos sofreram a modernização e todas as suas consequências desestabilizadoras de forma muito mais lenta e em uma sucessão que lhes foi benéfica (Lapalombara, 1973; Ward e Rustow, 1968; Coleman, 1965; Pye e Verba, 1969; Lapalombara e Weiner, 1972).

No entanto, ao analisar o processo de desenvolvimento político norte-americano, Huntington surpreende. Segundo ele, os Estados Unidos chegaram a um resultado institucional bem diferente do europeu porque não partiram do feudalismo e, portanto, não teria existido nesse país a mesma necessidade de centralização política que a Europa feudal enfrentou. Além disso, possuíam uma sociedade que já era moderna, o que não teria exigido um grande papel do Estado na mudança dos costumes e da estrutura social. A ideia de que, nos Estados Unidos, todas as pessoas já nasciam iguais não era nenhuma novidade, mas o que causa assombro em Huntington é a compreensão de que 
essas características produziram nesse país um desenho institucional antiquado e sem nenhuma inovação. A balança de poderes do sistema norte-americano é vista pelo autor como uma relíquia, um resquício da organização feudal, uma estrutura anacrônica que sobreviveu graças às baixas diferenças entre classes, mas que talvez gerasse os maiores problemas que enfrentavam no presente: desafios raciais, da Guerra Fria e da pobreza (Huntinton, 1975, p. 146). Portanto, a própria identidade de país desenvolvido dos Estados Unidos - isto é, de que possuiria instituições políticas eficientes e fortes - é questionada por Huntington. Como entender essa suavização da própria identidade? $\mathrm{O}$ papel que teve a questão da instabilidade/estabilidade na representação das sociedades em mudança e na própria definição de desenvolvimento político indica uma explicação plausível. A análise concreta da força e da eficiência das instituições norte-americanas pôde ser complexificada 108 e relativizada justamente porque não era mais nesse vetor em que se baseava a diferenciação entre âncoras e velas; a estabilidade versus a instabilidade que forneceu o novo referencial para a construção de uma identidade antitética assimétrica ${ }^{6}$. Ou seja, a complexificação do tema em Huntington é entendida aqui como um indício de que não é a veracidade da afirmação de que os países politicamente desenvolvidos são aqueles em que há instituições eficientes e fortes o que está em jogo. Na realidade, esse não é o ponto-chave da distinção que Huntington pretende realizar. Seu interesse maior está em diferenciar as instituições políticas que são estáveis das instáveis.

Antes de prosseguirmos, porém, uma observação é necessária. Foi mostrado como Huntington rompe com os teóricos clássicos ao diferenciar desenvolvimento polí-

\footnotetext{
${ }^{6}$ Sobre essa noção, ver Koselleck (2006).
} 
tico de modernização e, além disso, como compreende a modernização enquanto fenômeno essencialmente desestabilizador. Além disso, a própria distinção entre países desenvolvidos e sociedades em mudança é realizada com base no binômio estabilidade/instabilidade ${ }^{7}$. Por esse motivo, entende-se aqui que Huntington rompe com a linguagem teórica anterior, bem como promove um novo eixo em torno do qual o debate se reorganizará. Huntington dissocia o debate da instabilidade nos países pobres daquele sobre o progresso ou a modernização. Se a instabilidade, na sua abordagem marginal pelo pensamento clássico, estava imbricada em uma discussão sobre a transformação global desses países, essa associação não mais será necessária. A discussão e a representação dos países pobres nos termos da segurança e da instabilidade podem seguir seu caminho divorciadas do debate sobre o desenvolvimento econômico e a modernização.

A seguir, analisa-se como Fukuyama desmonta o esforço de Huntington em purificar o conceito de desenvolvimento político dos processos de participação e democratização.

\section{Francis Fukuyama: a democracia revisitada}

O conflito de perspectivas entre Huntington e Fukuyama desponta facilmente à primeira vista: se o principal desafio do primeiro foi desvencilhar o processo de modernização do desenvolvimento político, purificando com isso o último conceito de critérios tais como participação política e democratização, o segundo, por sua vez, ambicionou reinserir a democracia como ideal normativo a ser perseguido e atingível. Enquanto o primeiro afirmou que a moderni-

\footnotetext{
${ }^{7}$ Apesar de não ter sido objeto de investigação deste artigo, deve-se ressaltar que também a análise do hiato entre o campo e a cidade e dos caminhos possíveis da construção da ordem política é realizada com base no eixo estabilidade/instabilidade (Huntington, 1968).
} 
zação era um destino incerto e que a decadência política era uma situação muito mais provável, o segundo defendeu que o triunfo da democracia liberal ocidental já era uma realidade e que atingiria, a longo prazo, todos os países. No pensamento de Huntington, os efeitos benéficos da modernização desaparecem da reflexão; para o de Fukuyama, o liberalismo representa nada menos que o fim da história. Meu objetivo aqui é verificar em que medida essa oposição preliminar resiste a uma análise aprofundada.

Fukuyama restitui o vínculo entre o desenvolvimento político e a democracia liberal; o autor chega até mesmo a afirmar em $O$ fim da história e o último homem que, mesmo quando instável, a democracia é a única aspiração política coerente. Segundo ele, haveria um notável consenso, em todo o mundo, a respeito da legitimidade da democracia liberal e, mais do que isso, ela constituiria "a forma final do governo humano": seria o estágio

110 final de evolução ideológica da humanidade, em suma, o fim da história. A racionalidade da adesão à democracia se explica pelas características que definem este sistema. Retorna-se aqui a análise que ele faz dos seres humanos para, nesta perspectiva, entender o apelo da democracia no seu pensamento.

Fukuyama afirma, a partir de uma leitura kojèviana de Hegel, que os seres humanos distinguem-se dos animais porque desejam o desejo dos outros homens, isto é, cada um quer o reconhecimento de si próprio como ser humano digno ou de valor (Kojève, 1947). O desejo de reconhecimento não é só uma característica especificamente humana, mas é também o motor do processo histórico. Segundo essa perspectiva, a relação entre os homens se ordena enquanto uma luta por reconhecimento. O conflito-chave da busca pelo reconhecimento está na possibilidade de se conseguir alcançá-lo efetivamente: o reconhecimento só é real quando advém dos pares ou de entes em igual con- 
dição, e tem pouco ou nenhum valor quando provém de um ser cuja humanidade não é admitida, por exemplo, os escravos. Dessa forma, relações de domínio e de servidão não atingem o fim perseguido, a saber, a obtenção do reconhecimento. É a insatisfação ou incapacidade de alcançar aquilo que é específico dos seres humanos que constitui a contradição das sociedades desiguais e, por outro lado, é a razão do engendramento de novas formas de governo; ou, como postula Fukuyama, da evolução para etapas mais avançadas da história.

Com base nessa perspectiva do ser humano e da evolução histórica, a democracia é definida como o sistema que permite a satisfação das aspirações humanas mais profundas e fundamentais, uma vez que ao efetivar politicamente a igualdade entre os homens, realiza simultaneamente a possibilidade da conquista mútua e universal do reconhecimento. A satisfação do desejo por reconhecimento é justamente o que reinsere a democracia no desenvolvimento político. Desenvolver-se politicamente é alcançar esse sistema livre de contradições internas fundamentais. Mais do que isso, o sistema democrático constitui o fim da história; ou seja, é a concretização de um princípio não aperfeiçoável, o último estágio possível para o desenvolvimento político.

A satisfação da aspiração humana mais profunda - o desejo de reconhecimento - é a razão pela qual a democracia seria o estágio final do desenvolvimento político e o sistema de alcance universal e difusão inevitável. A condição democrática é livre de contradições internas fundamentais, como nenhum outro sistema político conseguiu ou teria qualquer chance de alcançar. Dessa forma, inexistem alternativas viáveis à democracia e o triunfo desta em todos os países é inevitável a longo prazo.

A certeza do triunfo da democracia não quer dizer ausência de problemas e menos ainda falta de preocupação 
com a questão da estabilidade democrática; essas questões são recorrentes, ainda que se acredite que elas serão superadas futuramente, dada a inexistência de qualquer alternativa melhor e a impossibilidade desse princípio ser aperfeiçoado. O primeiro parágrafo de $O$ fim da história exemplifica como a questão da democracia aparece o tempo todo no pensamento de Fukuyama acompanhada da preocupação com a estabilidade:

Entretanto, mais do que isso, eu afirmava [no artigo] que a democracia liberal pode constituir o "ponto germinal da evolução ideológica da humanidade" e "a forma final de governo humano" e, como tal, constitui "o fim da história”. [...] Não significa que as estáveis democracias atuais, como os Estados Unidos, a França ou a Suíça, estejam isentas de injustiça e sérios problemas sociais. Porém são problemas de implementação incompleta dos princípios de liberdade 112 e igualdade, nos quais essas democracias se baseiam, e não oriundos de falhas nos próprios princípios. Embora alguns países contemporâneos não chegassem a alcançar uma democracia liberal estável, e outros revertessem para outras formas mais primitivas de governo, como a teocracia ou a ditadura militar, não seria possível aperfeiçoar o ideal da democracia liberal (Fukuyama, 1992b, p. 11).

A citação acima mostra como a estabilidade é uma questão presente na observação dos países que já possuem democracias consolidadas, assim como daqueles recém-democratizados.

Além disso, no mesmo trecho, Fukuyama reconhece a possibilidade de que, uma vez alcançada a forma final de governo humano, os países possam "regredir"8 para

\footnotetext{
8 A palavra "regressão" aparece na edição portuguesa (Fukuyama, 1999). Originalmente, o autor escreve: "might lapse back into other, more primitive forms of rule like theocracy or military dictatorship" (Fukuyama, 1992a).
} 
formas de governo mais "primitivas". Assim, apesar de ter reinserido a democracia no desenvolvimento político, ele não mantém as demais asserções da perspectiva clássica sobre o desenvolvimento político que o concebia como cumulativo e irreversível $^{9}$. O progresso está, de fato, combinado com a possibilidade de regressão. Dessa forma, a democracia aparece o tempo todo articulada à questão da instabilidade. É com esse viés que ele analisa a transição para a democracia no sul da Europa, na América Latina e nos países da antiga União Soviética (Fukuyama, 1992b, pp. 40, 41, 65-66).

Fukuyama reinsere a democracia na definição de desenvolvimento político e reafirma esse sistema como o destino final de todos os países; mas mantém, em certo sentido, parte da argumentação de Huntington, já que esse último, apesar de questionar a visão de que a democracia seria inevitável, afirma que a decadência política era sempre um resultado possível. De fato, o sentido da regressão pensada por Fukuyama se aproxima, em alguns trechos, da definição de decadência política de Huntington. O inverso da democracia estável seria a agitação, a guerra civil e a desintegração (Fukuyama, 1992b, pp. 65-66). No entanto, a citação transcrita anteriormente apresenta um outro sentido para o regresso: o retorno às formas de governo mais primitivas.

Também na análise dos Estados fortes comunistas ou dos Estados autoritários está presente uma reflexão a respeito de como é possível uma transformação do sistema de governo vigente. A instabilidade desses regimes é apresentada como uma crise das ideias ou crise de legitimidade.

\footnotetext{
${ }^{9}$ A partir da obra de Huntington começa-se a criticar essa visão simplista que os clássicos teriam do desenvolvimento. Alguns autores que, de fato, apresentavam uma versão bastante otimista da modernização eram Lerner (1964); Almond e Coleman (1969) e Shils (1960).
} 
Para compreender as verdadeiras fraquezas do Estado soviético, então, o problema econômico deve ser situado no contexto de uma crise muito maior, a crise da legitimidade do sistema político como um todo (Fukuyama, 1992b, p. 58).

Ou seja, aquilo que constitui a fraqueza ou a instabilidade dos Estados fortes é a falta de legitimidade. Dessa forma, a crença na capacidade de perpetuação dos sistemas autoritários ou de que os Estados fortes seriam mais estáveis que os democráticos desmontou-se assim que a antiga União Soviética teve que lidar com questionamentos à legitimidade do Estado comunista.

A ausência de autoridade legítima significou a falta de um princípio mais alto para o qual o governo autoritário pudesse apelar em caso de fracasso em qualquer área da sua 114 política. Alguns comparam a legitimidade a uma espécie de reserva de dinheiro. Todos os governos, democráticos e autoritários, têm seus altos e baixos, mas somente os governos legítimos possuem essa reserva para ser utilizada nos tempos de crise (Fukuyama, 1992b, p. 69).

Em suma, o contraste entre a preocupação de Fukuyama com a instabilidade do regime democrático e suas explicações para a não perpetuação do Estado forte indica que, ainda que a instabilidade da democracia seja uma questão constante, esse sistema é visto como instável a curto prazo; mas, uma vez que se baseia em um princípio mais nobre e legítimo capaz de lhe garantir resistência à crise, possui maior resiliência a longo prazo (Fukuyama, 2006a).

A seguir discute-se o efeito da reinserção da democracia na compreensão das identidades dos países pobres e dos países ricos. 


\section{Históricos versus pós-históricos}

A questão do reconhecimento é crucial para a definição da democracia no pensamento de Fukuyama e é também por meio dessa noção que ele entende as relações internacionais. A luta pelo reconhecimento existe igualmente entre países e os conduz à disputa, à guerra e ao imperialismo. A democracia é a solução doméstica para a consecução do reconhecimento recíproco e igualmente a saída para a disputa no nível internacional. Somente a relação entre democracias liberais viabiliza o reconhecimento mútuo da legitimidade das nações. Dessa forma, Fukuyama entende que a guerra e o imperialismo são fenômenos específicos das relações entre países não democráticos e, eventualmente, de um desses países com um outro que possui um regime democrático; mas, raras vezes, ocorrem entre duas democracias liberais, já que as sociedades capitalistas democráticas não necessitam da guerra ou do imperialismo para buscar o reconhecimento. Na medida em que não há necessidade de luta por reconhecimento, as relações entre os países pós-históricos estão baseadas no eixo econômico.

Se as democracias podem se relacionar sem os problemas da disputa, da guerra ou do imperialismo, o mundo pós-queda do Muro de Berlim, mais exatamente, o mundo após a "terceira onda" de democratização, traria então a promessa - ao menos para um observador que escreve entre 1989 e 1992 - de ser um espaço cada vez mais livre de crises, conflitos e instabilidades? Infelizmente, se a imagem dos países pós-históricos permite vislumbrar um futuro mais pacífico, outra é a consequência da representação dos países que ainda se encontram na história.

Quais são as implicações do fim da história para as relações internacionais? Evidentemente, a grande massa do terceiro mundo permanece comprometida com a história, e será um terreno de conflito por muitos anos ainda (Fukuyama, 1989). 
De fato, aqueles países que Fukuyama chama acima de "terceiro mundo" aparecem o tempo todo, no artigo e no livro, associados às disputas pelo poder, aos conflitos religiosos, nacionais e ideológicos, às guerras, à injustiça e à pobreza.

Reafirma-se, com isso, a divisão huntingtoniana entre países desenvolvidos estáveis e sociedades em mudança instáveis. Apesar da compreensão do que constitui o desenvolvimento político haver se transformado com a introdução da questão do reconhecimento e a reintrodução da democracia, isso não altera a compreensão daquilo que distingue países ricos e países pobres: a estabilidade. Mais do que uma divisão entre históricos e pós-históricos, instáveis e estáveis, belicosos e pacíficos, não é qualquer instabilidade, guerra ou imperialismo que Fukuyama está prognosticando para o mundo pós-Guerra Fria, mas é justamente um tipo de insegurança que atinge o "primeiro mundo". Aquele mun-

116 do pós-histórico que já superou os problemas da história sofre ainda do mal de ter que conviver com um "terceiro mundo", gerador de conflitos que não consegue controlar. Segue abaixo o prognóstico do autor sobre o mundo do fim da história:

Isso não implica, de forma alguma, o fim do conflito internacional per se. O mundo neste momento estaria dividido entre uma parte que seria histórica e uma parte pós-histórica. Conflito entre Estados ainda na história, e entre esses Estados e os que estão no fim da história ainda seria possível. Ainda haveria um alto, e talvez crescente, nível de violência étnica e nacionalista, já que esses impulsos estão incompletamente exauridos, até mesmo em parte do mundo pós-histórico. Palestinos e curdos, sikhs e tameis, católicos irlandeses e valões, armênios e azeris, continuarão a ter seus ressentimentos não resolvidos. Isso implica que terrorismo e guerras de libertação 
nacional continuarão a ser um item importante da agenda internacional (Fukuyama, 1989).

Outros pontos de colisão entre o mundo histórico e o mundo pós-histórico que aparecem no livro são: o petróleo, a imigração e a proliferação de tecnologia.

De um lado, Fukuyama reinsere a democracia na definição de desenvolvimento político, de outro a discussão sobre ela aparece sempre acompanhada da preocupação com a estabilidade. Ao mesmo tempo, a imagem sobre o "terceiro mundo" que emerge a partir dessa nova compreensão do desenvolvimento político continua sendo a da instabilidade. Ambas proposições indicam que aquilo que Fukuyama entende por desenvolvimento político é mais do que democratização. Para a consagração do progresso político outro processo deve estar associado à aquisição de democracia: a estabilização.

Uma análise de obras mais recentes de Fukuyama reafirma a hipótese que o pensador não entende desenvolvimento político com base exclusivamente na democracia. A insuficiência da democracia enquanto critério único para descrever o desenvolvimento político aparece, primeiro de tudo, em sua própria argumentação a respeito da importância do legado de Huntington. Segundo ele, Ordem política nas sociedades em mudança foi o último esforço sério para elaborar uma grande teoria do desenvolvimento político. A literatura sobre a transição para a democracia trata de um aspecto do desenvolvimento político, mas não faz uma teoria abrangente sobre esse processo (Fukuyama, 2006a).

Além disso, as obras recentes do autor dedicam-se muito menos à questão da democratização dos países históricos, do que à estabilização desses países (Fukuyama, 2004; 2005; 2006b). Ele afirma que esses países constituem o mais importante problema para a ordem internacional 
desde o fim da Guerra Fria, pois são a fonte de abusos de direitos humanos, de ondas de emigração, de ataques aos vizinhos, de drogas, de aids, de terrorismo e estão por trás de várias crises do sistema internacional entre 1989 e 2001. Para agravar a situação, desde o 11 de Setembro esses Estados se tornaram prioridade global para segurança e assustam muito mais diretamente o "mundo desenvolvido". A citação a seguir explica a dimensão do problema atualmente:

Os ataques mostraram as maneiras pelas quais a violência havia se democratizado: a possibilidade de combinar o islamismo radical com armas de destruição em massa de repente passou a implicar que eventos ocorridos em partes distantes e caóticas podiam ser intensamente importante para os Estados Unidos e outros países ricos e poderosos (Fukuyama, 2005, p. 124).

Tal preocupação, reforçada pela instabilidade gerada por esses países, promoveu a inserção do problema da capacidade institucional, isto é, a capacidade dos Estados de planejar e de executar políticas. A partir dessa nova abordagem institucional, os Estados até então compreendidos como ainda presos à história começam a ser definidos como Estados fracos ou fracassados, sendo a "fraqueza” entendida como

falta de capacidade institucional para implementar políticas e forçar o respeito a estas, com freqüência causada pela subjacente falta de legitimidade do sistema político como um todo (Fukuyama, 2005, p. 128).

Reinsere-se, portanto, o tema, marcadamente huntingtoniano, da estabilidade das instituições na questão do desenvolvimento político. É verdade que essa questão não exclui 
a ausência de democracia enquanto causa dos problemas desses países, já que, para Fukuyama, a falta de legitimidade seria a fonte frequente dessa fraqueza institucional ${ }^{10}$.

Portanto, percebe-se no pensamento recente do autor de $O$ fim da história uma preocupação muito mais intensa com a questão da instabilidade somada a uma nova questão da capacidade institucional do que com o debate sobre a ausência de democracia dos Estados históricos. Apesar de ter reinserido a democracia no desenvolvimento político, a instabilidade, tal qual em Huntington, ainda é o ponto que mais interessa na análise desses países. Além disso, Fukuyama intensificou sua preocupação com a regressão - questão análoga à noção de decadência política de Huntington - ao focar grande parte das pesquisas recentes nesse fenômeno, além de aprofundar a sua compreensão teórica-conceitual do problema a partir da noção de Estado fraco ou fracassado.

Será que existe uma adoção consciente das ideias do professor pelo aluno? A análise do prefácio que Fukuyama (2006) fez para a reedição de Ordem política nas sociedades em mudança indica que esse último, de fato, ainda considera a obra de Huntington fundamental e tem consciência de como suas perspectivas se aproximam.

Fukuyama inicia o prefácio perguntando-se como podemos avaliar os argumentos de Huntington quarenta anos depois. Segundo ele, a experiência histórica neste período reafirma diversas asserções expostas em Ordem política nas sociedades em mudança: os piores casos de instabilidade continuam ocorrendo nos estágios iniciais da modernização; a mobilização social mais acelerada que o processo de institucionalização política continua um

\footnotetext{
${ }^{10}$ Ele associa a legitimidade ao sistema democrático do seguinte modo: "Embora historicamente tenha havido muitas formas de legitimidade, no mundo de hoje, a única fonte séria de legitimidade é a democracia." (Fukuyama, 2005, p. 45).
} 
grande problema atual; o desenvolvimento político segue lógica própria independente do desenvolvimento econômico ${ }^{11}$ e a ordem política e instituições políticas são precondições para o crescimento econômico dos países pobres. O ponto mais interessante da revisão de Fukuyama é que, segundo ele, Huntington revelou-se extremamente perspicaz ao focar na decadência política, fenômeno que tem sido bastante frequente no mundo pós-Guerra Fria, como atestam os casos de colapsos estatais e de Estados em processo de fracasso. A equivalência entre decadência e fracasso é realizada, portanto, pelo próprio Fukuyama, que afirma ainda que a tese sobre a decadência política não precisa ser corrigida, mas sim estendida de modo a inserir, para além do descompasso entre modernização e institucionalização, dilemas do sistema internacional contemporâneo que enfraquecem os Estados, como, por exemplo, a interdição ao recurso à violência, a facilidade 120 com que produtos ilegais e atividades criminais cruzam as fronteiras e o fornecimento direto de serviços por doadores externos; processos que impediriam, segundo essa perspectiva, a construção do Estado tal como ocorreu em outras partes do mundo.

\section{Considerações finais}

Enquanto Huntington diferencia modernização e desenvolvimento político e exclui o projeto de transformação global da sociedade do programa de obtenção de uma ordem política, Fukuyama retoma o objetivo de transformação mais ampla, pois reinsere a democracia no escopo

\footnotetext{
${ }^{11}$ Verifica-se aqui, portanto, que Fukuyama confirma a distinção lógica entre desenvolvimento político e desenvolvimento econômico (distinção, aliás, que já havia sido promovida antes de Huntington), mas não a distinção entre desenvolvimento político e modernização em geral e, mais especificamente, democratização. Para argumentações anteriores a respeito da distinção entre desenvolvimento político e econômico, ver LaPalombara (1973) e Ward e Rustow (1968), obras que foram publicadas em 1963 e em 1964, respectivamente.
} 
do conceito de desenvolvimento político. Essa divergência tem consequências no modo com que cada um desses cientistas entende a questão da instabilidade. Segundo Huntington, ela é resultado da ausência da ordem política, ou melhor, de um processo de mobilização mais acelerada do que a institucionalização. Fukuyama, por sua vez, registra múltiplas facetas do que seria a instabilidade. Em todo caso, em mais de um trecho, a instabilidade aparece relacionada à ausência de democracia, sendo vista, então, enquanto possibilidade de regressão a formas de governo mais primitivas - como resultado da crise de legitimidade - ou, ainda, como situação intrínseca dos países não democráticos ou presos à história.

Ainda assim, seria apressado afirmar que, do mesmo modo como ocorria até início da década de 1960, qualquer problematização da instabilidade desses países apareceria em Fukuyama interligada à discussão a respeito das possibilidades de transformação global, ou mais exatamente, da mudança do sistema de governo dessas sociedades. O debate sobre a instabilidade encontra uma grande via de vazão no tema da construção de Estados e, como foi visto, a promoção da democracia nesses países a curto prazo não é uma problemática presente em seu pensamento, nem mesmo quando os efeitos instáveis desse regime estão em causa.

Talvez a ausência da discussão democrática no presente esteja diretamente relacionada à certeza de sua vitória a longo prazo. Se o triunfo é certo, ainda que em um futuro longínquo, é possível reduzir em boa medida a ansiedade a respeito da construção de uma nova ordem. Além disso, diferentemente dos clássicos do desenvolvimento político, a aposta na democracia não é acompanhada de uma simplificação sobre os obstáculos para a instalação desse regime, sobretudo, na promoção externa da democracia nos países pobres. Segundo Fukuyama, a democratização 
só se efetiva caso exista, necessariamente, uma demanda interna por legitimidade. Além disso, os países desenvolvidos não possuem nenhuma experiência bem-sucedida de construção de Estados a partir de forças exteriores, menos ainda de democracia.

Em suma, Fukuyama e Huntington se assemelham em relação à identificação entre países pobres e instabilidade e ao interesse pela decadência ou regressão/fracasso. Outra afinidade teórica é a aposta no fortalecimento do Estado como solução para a instabilidade. Essas semelhanças colocam questões de primeira ordem para a teoria: por que uma nova definição do desenvolvimento político, que assume contornos maiores do que a mera ordem, ou mais diretamente, do que a estabilidade, não foi suficiente para mudar o foco sobre os países pobres e, mais do que isso, sua identidade predominantemente relacionada à questão da instabilidade? Ou seja, por que um novo otimismo sobre o 122 resultado final do processo em curso nesses países não significou uma guinada no olhar e na definição do que são os países não desenvolvidos politicamente?

Este artigo demonstra como, na realidade, ao invés da questão da democratização provocar uma guinada analítica e empírica, Fukuyama apresenta preocupações, ainda mais intensas, com a instabilidade desses países, já que, segundo ele, esses problemas afetam mais diretamente os países do “primeiro mundo". Será possível entender o foco ampliado na instabilidade e a aposta nas instituições como mero efeito do 11 de Setembro? Mesmo se essas preocupações já apareciam em 1989 e, desde então não encontraram nenhuma formulação inovadora, tão-somente se reforçou o rebaixamento do interesse democrático?

Uma última observação vale a pena ser feita nesta análise do pensamento desses dois autores: a da reinserção da democracia. Além de uma argumentação de que os conflitos dos países pobres afetam mais diretamente os países 
desenvolvidos, Fukuyama se distingue ainda por ampliar o foco da atenção dirigido à África, Ásia e América Latina. Se Huntington afirma que a modernização não é um interesse - do cientista ou do policymaker - e se restringe ao fenômeno institucional, também os clássicos apresentam um foco mais restrito do que importa à teoria do desenvolvimento. Neste último caso, as instituições é que estavam ausentes da análise, em parte por causa da rejeição que o behaviorismo naquela época tinha em relação ao institucionalismo na ciência política ${ }^{12}$. É interessante notar, portanto, que é peculiar a Fukuyama não apenas uma preocupação mais intensa com os efeitos da instabilidade, mas também um foco de atenção ampliado ao país pobre: nem Lerner, Almond e Coleman, Deutsch ou Shils, nem Huntington se interessaram tanto pela modernização e pela institucionalização política.

\section{Natália Nóbrega de Mello}

é mestre em Ciência Política pela FFLCH/USP e professora da FMU e do Unibero.

\section{Referências bibliográficas}

ALMOND, G.; COLEMAN, J. 1969. A política das áreas em desenvolvimento.

Rio de Janeiro: Freitas Bastos.

COLEMAN, J. (org.). 1965. Education and political development. Princeton:

Princeton University Press.

DEUTSCH, K. 1961. "Social mobilization and political development". The American Political Science Review, vol. 55, no 3, pp. 493-514.

FUKUYAMA, F. 1989. "The end of history." The National Interest, vol. 16, Summer, pp. 3-18. . 1992a. The end of history and the last man. New York: Free Press. . 1992b. O fim da história e o último homem. Rio de Janeiro: Rocco.

\footnotetext{
${ }^{12}$ Ver Lerner (1964), Almond e Coleman (1969) Deutsch (1961) e Shils (1960a; 1960b). O último chega a analisar as instituições políticas em si, ainda que a análise se concentre muito mais na modernização e nos seus efeitos políticos.
} 
. 1999. O fim da história e o último homem. Lisboa: Gradiva.

. 2004. "The imperative of state building". Journal of Democracy, vol.

$15, \mathrm{n}^{\circ} 2$, pp. $17-31$.

2005. Construção de Estados: governo e organização no século XXI.

Rio de Janeiro: Rocco.

. 2006a. "Foreword". In: HUNTINGTON, S. Political order in changing societies. New Haven: Yale University Press.

2006b. America at the crossroads: democracy, power, and the neoconservative legacy. New Haven: Yale University Press.

HUNTINGTON, S. 1965. "Political development and political decay". World Politics, vol. 17, n 3, pp. 386-430.

. 1975. Ordem política nas sociedades em mudança. São Paulo: Edusp.

1994. A terceira onda: a democratização no final do século XX. São Paulo: Ática.

KENSKI, H. 1975. "Teaching Latin American politics at American Universities: a survey”. Latin American Research Review, vol. 10, no 1, pp. 89-104.

KOJÈVE, A. 1947. Introduction à la lecture de Hegel. Paris: Gallimard.

KOSELLECK, R. 2006. "A semântica histórico-política dos conceitos anti124 téticos assimétricos”. In: Futuro passado: contribuição à semântica dos tempos históricos. Rio de Janeiro: Contraponto.

LAPALOMBARA, J. (org.). 1973. Burocracia y desarrollo político. Buenos Aires: Editorial Paidos.

; WEINER, M. (orgs.). 1972. Political parties and political development. Princeton: Princeton University Press.

LERNER, D. 1964. The passing of traditional society: modernizing the Middle East. New York: Free Press.

MONTEIRO, L. N. 2006. O conceito de Estado fracassado nas relações internacionais: origens, definições e implicações teóricas. Dissertação de mestrado em Relações Internacionais. São Paulo: PUC-SP.

POCOCK, J. 2003. Linguagens do ideário político. São Paulo: Edusp.

PYE, L.; VERBA, S. (orgs.). 1969. Political culture and political development. Princeton: Princeton University Press.

SHILS, E. 1960a. "Political development in the New States". Comparative Studies in Society and History, vol. 2, no 3, pp. 265-292.

1960b. "Political development in the New States II". Comparative Studies in Society and History, vol. 2, no 4, pp. 379-411.

WARD, R.; RUSTOW, D. (orgs.). 1968. Political modernization in Japan and Turkey. Princeton: Princeton University Press. 
WIARDA, H. 1991. "Comparative politics, past and present". In: New directions in comparative politics. Boulder: Westview Press, pp. 3-25. 1998. "Is comparative politics dead? Rethinking the field in the post-Cold Era”. Third World Quarterly, vol. 19, no 5, pp. 935-949.

\section{Outros materiais}

FUKUYAMA, F. 2008. "Samuel Huntington, 1927-2008.". Disponível em $<$ http://www.the-american-interest.com/contd/?p=688>. Acesso em 24 jul. 2010.

SCHMITTER, P. 1991. "Comparative politics at the crossroads". Disponível em: <http://www.march.es/ceacs/publicaciones/working/ archivos/1991_27_en.pdf>. Acesso em 24 jul. 2010. 


\section{O DESENVOLVIMENTO POLÍTICO EM HUNTINGTON E FUKUYAMA}

\section{NATÁLIA NÓBREGA DE MELLO}

$\mathrm{O}$ artigo contrasta as teses de Huntington e Fukuyama sobre desenvolvimento político. As obras analisadas, Ordem política nas sociedades em mudança e $O$ fim da história, inscrevem-se entre duas conjunturas decisivas - 1968 e 1989. Huntington desmontou a equivalência entre desenvolvimento político e modernização e Fukuyama reafirmou a democracia como o destino de todos os países e, desse modo, como o fim da história. Nesta comparação, dois eixos se sobressaem: o contexto de produção das obras e a alternância entre os polos teóricos da democracia e da estabilidade. Procura-se demonstrar como, apesar de reinserir a democracia no desenvolvimento político, a instabi208 lidade continua a ser um foco privilegiado de análise no pensamento de Fukuyama.

Palavras-chave: Desenvolvimento político; Democracia; Estabilidade; Países pobres.

\section{HUNTINGTON AND FUKUYAMA ON POLITICAL DEVELOPMENT}

The article contrasts the theories of Huntington and Fukuyama on political development. The analyzed works, Political order in changing societies and The end of history, fall between two decisive historical moments - in 1968 and 1989. Huntington disassembled the equivalence between political development and modernization; Fukuyama reaffirmed democracy as the destiny of all countries and, as such, it is the end of history. In this comparison, two axes call our attention: the production context of these works and the alternation between the theoreticals poles of democracy and stability. The article shows how, although reenters democracy in the 
political development theory, instablility remains a prime focus of analysis in Fukuyama's thought.

Keywords: Political development; Democracy; Stability, Poor countries. 